\title{
Testing the Trust Game with undergraduates: An experiment with wealth heterogeneity
}

Caballer-Tarazona, María ${ }^{\text {a }}$; García-Gallego, Aurorab and Rodrigo-González, Amalia ${ }^{\mathrm{c}}$ ${ }^{a}$ Applied Economics Department, Valencia University, Spain, ${ }^{b}$ LEE and Economics Department, Universitat Jaume I, Spain, ${ }^{\mathrm{c}}$ Corporate Finance Department, Valencia University, Spain

\begin{abstract}
Trust, reciprocity and a fair distribution of resources are cruzial in the sustainability of any economic system. As a matter of fact, those are values that should be promoted among the new generations, especially among university students enrolled in degrees that are related to economics.

Under this context, we are interested in enhancing criticism and active reflection among undergraduates with respect to social values. With such a goal in mind, we designed a two step classroom task that includes playing the Trust Game (TG) in the first place and, second, a discussion activity.

This paper is an extension of Caballer-Tarazona et al. (2016) with a novelty: A new treatment is introduced in which subjects have information about the cumulated wealth of their partners.

As a complement of the educational purpose of the task, data collected during the experiment has been used to test three hypotheses on trust and reciprocity among students.

Two main results emerge:First, information has no effect on trust and reciprocity decisions. And second, in median a gender effect in such decisions is found.
\end{abstract}

Keywords: Trust game; experiment; social values; trust; reciprocity. 


\section{Introduction}

Trust, reciprocity and a fair distribution of resources are cruzial in the sustainability of any economic system. Moreover, those are basic values for putting up a rich social capital within the society (Diettrich, 2015). As a matter of fact, those are values that should be promoted among the new generations, especially among university students enrolled in degrees that are related to economics, since trust and reciprocity are basic elements in economic decision making.

We are convinced that such moral and ethics values which directly affect economic decisions should be promoted among university students in general, and especially among students within economic degrees. Therefore, we propose in this paper a classroom activity aimed to create an open framework to allow students to develop a critic opinion and autonomous reflection in social values, specifically on trust and reciprocity. Previous experiences show the efficacy of implementing experimental games as a classroom activity with educational aims (see Rodrigo-González and Caballer-Tarazona, 2015).

With this goal in mind, we designed a classroom activity based on experimental economics. The literature provides some experiments aimed at testing trust and reciprocity behavior (Berg et al. 1995 or McCannon, 2014). We follow the work by Caballer-Tarazona et al. (2016) where students take decisions without knowing the partner's cumulated wealth. Specifically, we extend that experiment by including a new treatment in which students are provided with information about cumulative wealth. Thus, they take decisions under wealth heterogeneity conditions. It allows us to evaluate the wealth heterogeneity effect on trust and reciprocity.

The task was carried out in the course of "Introduction to Bachelor studies", that is placed in the first year, first semester of degrees in Business Administration and Tourism of the Faculty of Economics at the University of Valencia, Spain. The scope of this task is to study the effect that wealth information has on trust and reciprocity among undergraduates and to identify possible gender differences.

Our general target is to make students reflect about the behavioral dynamics in the context of the Trust Game (TG), and any ethics and moral values that could emerge from playing it.

\section{General framework}

We test the TG among undergraduates. In the TG, a trustor is endowed with an amount of money $E$. The trustor decides which part of the endowment $x \in(0, E)$ to send to an

\footnotetext{
${ }^{1}$ The course Introduction to Bachelor studies is a transversal subject that is aimed at facilitating the transition from student to the university environment, from a holistic approach that takes into account not only the competencies specifically on their degree, but also those related to the knowledge of the institution to which it belongs and its role in society.
} 
anonymous trustee. The amount $x$ is then multiplied by $n$ in the trustee's hands. The trustee then decides which amount $y \in(0,3 x)$ to return to the trustor. Consequently, the payoff of the trustor is $\pi_{t r}=E-x+y$, and that of the trustee is $\pi_{t e}=3 x-y$. Figure 1 shows the extensive form of this game, with thick lines showing the equilibrium path.

The game has two subgames. Subgame 1 is sorruounded by dotted lines and subgame 2 is the game itself. The strategy "no transfer" is a Nash equilibrium strategy of subgame 1, that is, the trustee does not return any amount to the trustor in equilibrium. Subgame 2 has a Nash equilibrium strategy in "no trust", for the trustor, i. e. not to give money at tall to the trustee. Thus, the subgame-perfect Nash equilibrium (no transfer, no trust) does not allow for any value creation nor reciprocity.

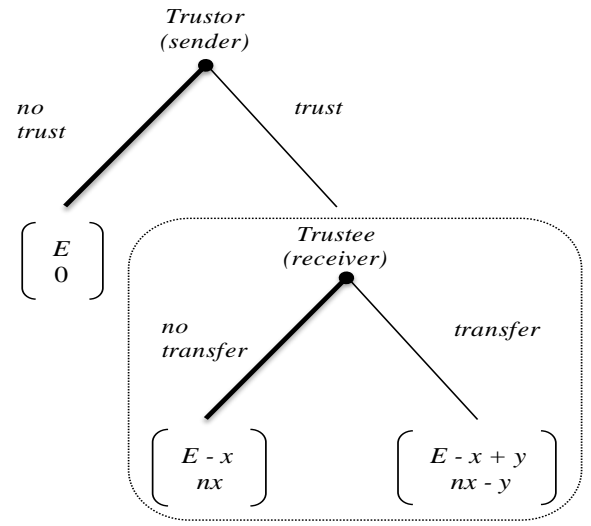

Figure 1. Extensive form of the TG implemented. Payoffs (up:Trustor; down:Trustee)

The experiment was run in LINEEX with 50 participants (20 males and 30 females). The experiment was programmed using z-Tree (Fischbacher, 2007). The activity was designed as a compulsory activity within the course "Introduction to Bachelor studies".

The session was carried out as follows: participants were first splitted in two groups and randomly assigned a role (trustor or trustee), then randomly matched at the beginning of each round. Anonymity was kept in order to prevent any trust-unrelated effect. In each round, both trustors and trustees are given an endowment of 50 ECUS. The trustor must decide how many ECUS to send to an anonymous trustee: an amount $x$ in the set $\{0,10$, $20,30,40,50\}$. The amount sent is then tripled in the trustee's hands. Finally, the trustree hast to choose the amount of ECUS that she wants to give to the trustor: a strategy $y$ in the set $\{0,10,20,30,40, \cdots \cdots, 200\}$ which satisfies $0 \leq y \leq 3 x+50$.

To capture the information effect on trust and reciprocity, the baseline treatment $\mathrm{T} 0$ is compared to a new treatment with private information (T1) that allows us to contrast the claiming that initial inequality in wealth may have an effect on trust and reciprocity. 


\subsection{Hypotheses on Trust and Reciprocity}

Denote as $\lambda_{0}$ and $\lambda_{1}$ the percentages of money sent by the trustors in treatments T0 and T1, respectively. As for trustees, denote as $R_{0}$ and $R_{1}$ the return rates in treatments $T 0$ and $T 1$, respectively. Three hypotheses we want to test: Hypothesis $\mathbf{1}\left(\mathbf{H}_{\mathbf{1}}\right)$. To have private information about the trustee's cumulated earnings has a positive effect on the trustor's decision on $\lambda=x / 50$. Hypothesis $2\left(\mathbf{H}_{2}\right)$. Private information about the trustor's cumulated earnings has a positive effect on trustee's decision on $R=\frac{y}{x}-1$. Hypothesis $3\left(\mathbf{H}_{3}\right)$. There is a gender effect, so that females and males behave differently in trust and return decisions.

\subsection{Session I: The TG repeated finitely in the Lab}

This first session of the experiment was structured as follows: (1) Hand delivering and reading instructions: Students were provided with instructions about the trust game ans the teacher read them loud (15 minutes). (2) The game: During 10 rounds, subjects played the trust game described in figure 1.(60 minutes). (3) A questionnaire: Open questions about students' opinions and perception about social values as well as for real meaning of the game (15 minutes).

\subsection{Session II: Discussion}

One week after playing the game, in a regular classroom, a second session took place in two phases: (1) Presentation: After delivering their single written dissertations on the chosen books, students were clustered in groups that have books in common. Each group shared opinions about contents, underlying the most interesting points, as well as likes and dislikes. They also summarized the content of the book and designed a speaker who explained the book to the rest of the participants (about 30 minutes). Finally, each speaker presented the corresponding book and answered their class-mate questions about the reading topic (about 30 minutes). (2) Connecting ideas: Students spent 30 minutes identifying the similarities between the real meaning of the experiment and the content of the books. First, each student individually wrote a note with his/her answers. Second, the teacher explained the TG theoretical predictions. Finally, she held conversations with students about fairness and opened vivid debate.

\section{Data analysis}

\subsection{Experimental data}

Figure 2 shows the histograms of the trustor's percentage sent and the trustee's return rate, per treatment. By testing $\mathrm{H}_{1}$ and $\mathrm{H}_{2}$ about a private information effect on agents' decisions, we fail to reject the null hypothesis at $5 \%$ by both Wicolxon rank sum test and median test in trustor and trustee samples. 
Result 1: Having private information about partner's earnings does not produce, in median, any change in trust and reciprocity decisions.

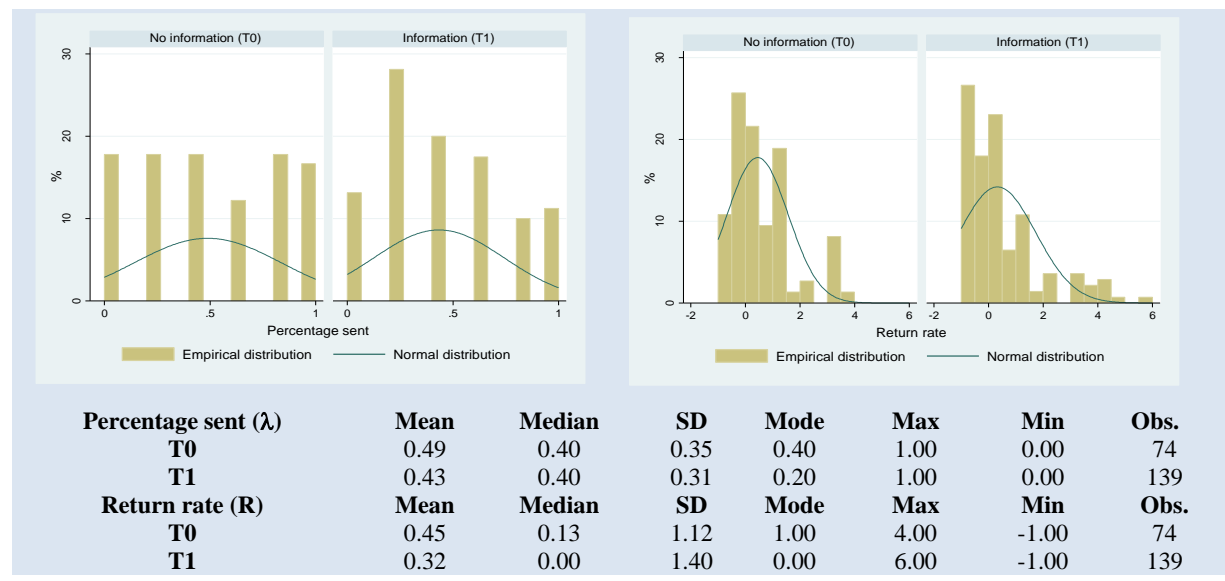

Figure 2. Relative frequency histograms (percentage send and return rate), by treatment

As figure 3 shows, trustor-females sent higher median amounts than males in T0, but hardly less in T1. The opposite happens about returning decision. Testing $\mathrm{H}_{3}$ leads next result:

Result 2: In median, gender differences are observed concerning percentages sent $(\lambda)$ in both treatments: women send higher amounts than males in T0 but the opposite occurs in $\mathrm{T} 1$. Regarding return rates $(\mathrm{R})$, gender differences are found in $\mathrm{T} 1$ : females returned higher amounts than males in $\mathrm{T} 1$.

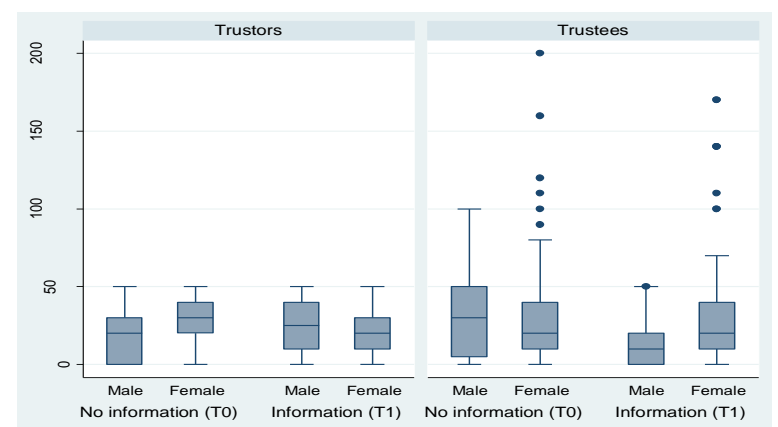

Figure 3. Distributions of type of players offers (by gender and treatment)

\subsection{The Questionnaire}

The questionnaire is divided into three blocks related to Gardner's multiple intelligence.The first block includes questions about intra and interpersonal intelligence. Students were asked their own feelings and their guessing about their partners' feelings in course of the TG. In particular, students ended the two following incomplete sentences by selecting the icon fitting better (sadness, indifference, happiness, malice, and anger). 
"In this experiment, I have felt ....."

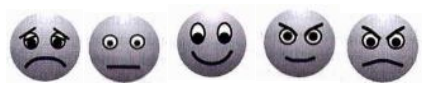

"I think that the people with whom I have played have felt...."

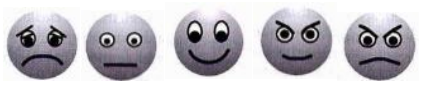

Interestingly, $45 \%$ of students marked the opposite box to their own feeling to indicate the partners' feeling (e.g. I'm happy, you're angry, or vice versa). In these cases, we suppose that students perceived the game's result as unfair, because one partner's happiness implied the other's anger.

Concerning students' propensity to solidarity, we provided them with the question "Which adjective describes you better?" Answers: selfish, egalitarian, and altruistic.

The most frequent answer was “egalitarian': $77.8 \%$ in T0 and $93.7 \%$ in T1. In T0, $16.7 \%$ of the subjects declared themselves as altruistic and only one student as selfish. In T1, $0.3 \%$ of the students declared themselves as altruistic. Figures $4 \mathrm{~b}$ and $4 \mathrm{~d}$ plot the solidarity propension declared by trustees after participating in the experiment. Notice that in T0 two thirds declared themselves as egalitarian, and in the treatment $\mathrm{T} 1$ all of them claimed to behave as egalitarian. As shown, there are differences between students' answered solidarity propension and real payback decisions in the game (return rate).

Regarding students' trustiness to others, they had to chose one of the statements below associated to three trust levels: low trust (LT), medium trust (MT), and high trust (HT).

$\square$ I only trust people that I already know. (LT)

$\square$ I am confident in some circumstances, especially when I do not have much to lose. (MT)

$\square$ In general, I trust people unless they show me that they do not deserve my trustiness. (HT)

Figures $4 \mathrm{a}$ and $4 \mathrm{c}$ plot the trustiness level declared by trustors. In T0 most (55\%) trustors marked HT, whereas in T1 half of the trustors selected LT. In addition, some differences between students' confidence level and decisions on the percentage sent in the game are observed. For instance, in median values, in figure 4a trustors 1, 3, and 9 sent amounts below the $50 \%$ of their endowment, but they had claimed that they trusted people as a matter of fact. In figure 4c, the discrepancy between facts and words is even more evident. As documented in related literature, we also looked for a possible friendship effect on trust and reciprocity behavior. For that purpose, we formulated an open question: "Would you have played in the same way if you partner had been a friend of yours?"

In T0, 55.5\% of students would have changed their offers, while only $34.4 \%$ in T1. In both treatments, students who would have changed their behavior argued that they would have been more generous if playing against a friend or, at least, they would have followed a 
collaborative strategy aiming at achieving equal earnings. Among the most frequent reasons given contained the words 'generosity', 'cooperation', and 'trust'. The rest of the students considered their behavior quite generous and, therefore, they would have followed a similar decision pattern if playing with a friend. However, three of those students declared that "friendship and business do not mix together".

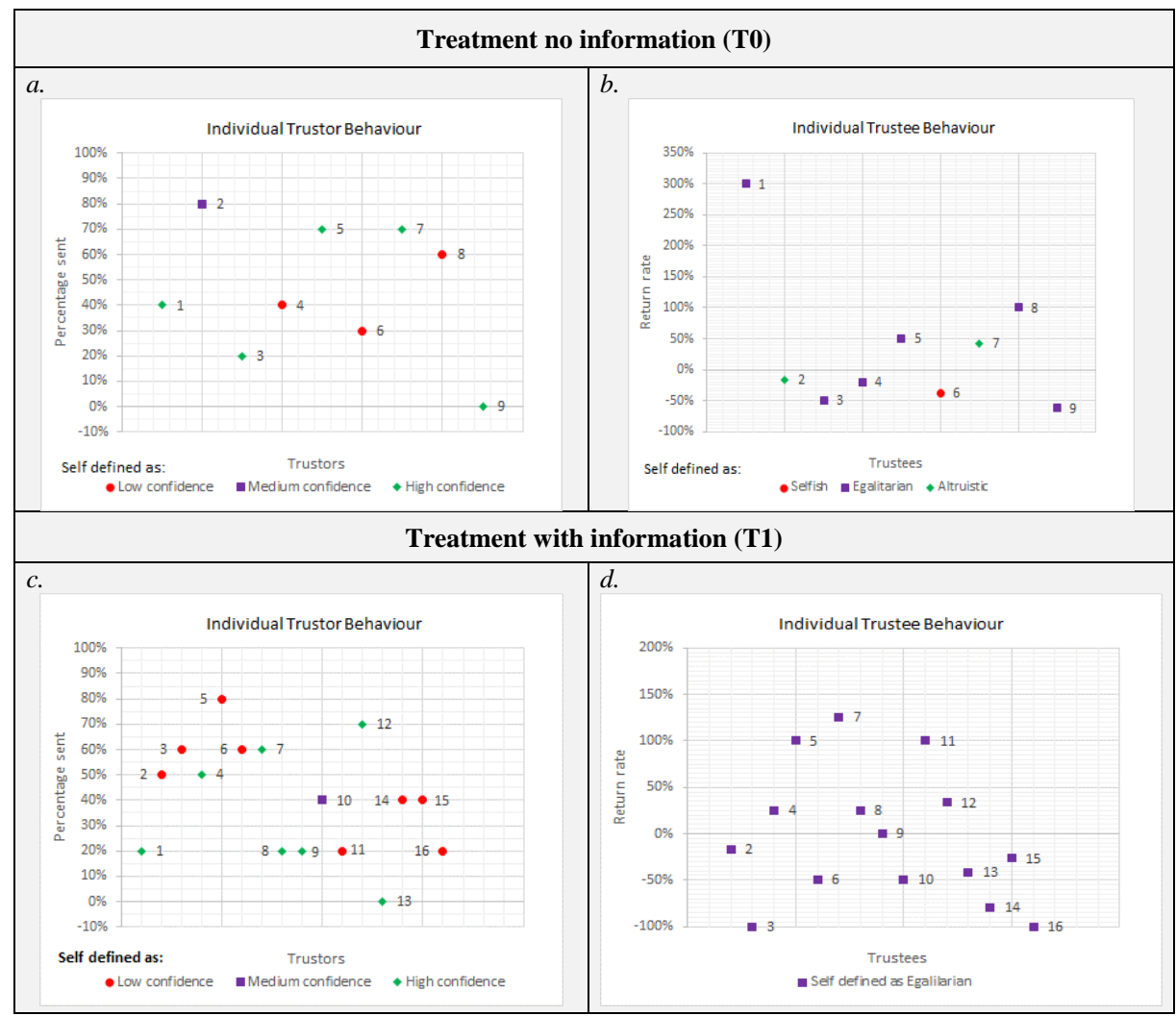

Figure 4. Differences between performed and declared behavior (median values)

The second block includes four open questions about logical-mathematical intelligence.

What do you think is the game's core? Answers: Producing profit. Distributing resources. Observing generosity. Making investments. Taking strategic decisions. Taking risky decisions.

Would you have played in the same way if you had been rewarded in cash? Why? Answers:In T0, $46.7 \%$ of the students declared that they would have played in a different way if earnings had been in cash, and $56.2 \%$ in T2. They argued that they would have been less generous, playing more prudently and taking less risk. In contrast, students who would kept their behavior claimed that they did their best, being aware of the game and trying to 
get the highest score in ECUS.

How would you have played in the opposite role? Why? Answers:We find a wide variety of poor and brief answers to this question (e.g. "I'd have played in the same way."), which does not allow us to identify a general conclusion for each role.

What do you think is the best strategy? Answers:Some students answered "I don't know". The $30 \%$ of students argued that without knowing the goal of the game it was not possible to identify the best strategy. However, a few students furnished interesting answers, which we cluster in two groups: (1) Collaborative strategy. The 56\% of students thought of sharing profits equitably. (2) Competitive strategy. The remaining $14 \%$ of students did not consider the partner's interest and shared the minimum possible. This strategy was based on the short term profit (profit per round).

The questionnaire finished with an existential intelligence question: Which values are important for you? Answers: respect, honesty, solidarity, equality, fairness, trust, ambition and loyalty.

\section{Discussion}

First, experimental data allow us to test the three formulated hypothesis. We found that the information about wealth heterogeneity between partners produces changes neither in trust nor reciprocity decisions, in median.

Regarding the third hypothesis, some gender differences were found. Specifically, women send higher amounts than males in T0, but the opposite occurs in T1. In addition, higher amounts of the return rate were sent by women in $\mathrm{T} 1$.

Second, the conclusion of the whole activity was carried out in the last session, which allowed students to reflect about the activity core and exposed very interesting interpretations of the activity.

In the last session, students were clustered in groups per book in common for the presentation. During twenty minutes they discussed and summarized the main contents of the book. Each group selected a spokesperson who presented the summary to the class. Afterwards, a short debate spontaneously emerged in the class.

To connect ideas each student handed in a note with two questions: What topic do the readings have in common? Answers: A social and egalitarian economy. A supportive model of economy based in cooperation and common good. Use resources for improving social well-being. Everybody deserves the same opportunities.

What is the link between the game and the readings? Answers: "Everybody takes advantage if we share resources". "Trust, justice and social equity". "Cooperation and trust as an essential element for archiving a proper wealth distribution and well-being for 
everybody". "Encouragement of a sustainability and egalitarian economy".

During this last part of the activity, we reached to engage students in a proactive participation and antonomous reflection, thus we accomplished our educational goal.

\section{Conclusions}

We focus on trust and reciprocity as fundamental elements in new economic contexts (e.g. collaborative economy, green economy or virtual economy). In order to understand new socio-economic paradigms, bachelors in economics must provide students with updated education. The activity presented here is a real stimulous for students' motivation that allows them to acquire and develop some essential skills like being able to think critically.

\section{References}

Berg, J., Dickhaut, J., and McCabe, K. (1995). Trust, reciprocity, and social history. Games and Economic Behavior 10, 122-142.

Caballer-Tarazona, M., García-Gallego, A., and Rodrigo-González, A. (2016). Promoting trust and reciprocity in the classroom. 8th annual International Conference on Education and New Learning Technologies, Barcelona, Spain. 4-6 July, 2016. ISBN: 978-84-608-8860-4. Publisher: IATED.

Diettrich, M. (2015). Gender differences in trust and reciprocity: evidence from a largescale experiment with heterogeneous subject. Applied Economics 47, 3825-3838.

Fischbacher, U. (2007). z-Tree: Zurich toolbox for ready-made economic experiments. Exp Econ 10, 171-178.

Gardner, H. (1983). Frames of mind: The theory of multiple intelligences. Basic Books, NY.

McCannon, B. (2014). Trust, reciprocity, and a preference for economic freedom: experimental evidence. Journal of Institutional Economics 10(3), 451-470.

Rodrigo-González A, and Caballer-Tarazona M. (2015). A model to assess students' social responsibility behavior within a classroom experiment. International Review of Economics Education 18, 62-82. 